\title{
Percolation in a Proton Exchange Membrane Fuel Cell Catalyst Layer
}

\author{
Stephen A. Stacy ${ }^{\mathrm{a}}$, Jeffrey S. Allen ${ }^{\mathrm{a}}$ \\ a Department of Mechanical Engineering-Engineering Mechanics \\ Michigan Technological University, Houghton, Michigan 49931, USA
}

Water management in the catalyst layers of proton exchange membrane fuel cells (PEMFC) is confronted by two issues, flooding and dry out, both of which result in improper functioning of the fuel cell and lead to poor performance and degradation. At the present time, the data that has been reported about water percolation and wettability within a fuel cell catalyst layer is limited. A method and apparatus for measuring the percolation pressure in the catalyst layer has been developed based upon an experimental apparatus used to test water percolation in porous transport layers (PTL). The experimental setup uses a pseudo Hele-Shaw type testing where samples are compressed and a fluid is injected into the sample. Testing the samples gives percolation pressure plots which show trends in increasing percolation pressure with an increase in flow rate. A decrease in pressure was seen as percolation occurred in one sample, however the pressure only had a rising effect in the other sample.

\section{Introduction}

Within a PEM fuel cell catalyst layer, water transport may occur via different processes, such as condensation, evaporation, and removal through the porous transport layer (PTL).(1) Flooding and dry out, are the two main issues of water management in the catalyst layer of PEM fuel cells, which can result to improper functioning of the fuel cell and lead to a poor performance of the fuel cell as well as degradation of materials.(2)

Research on water transport within PEM fuel cell catalyst layers thus far has mostly been model development rather than experimental. Water transport modeling efforts for the catalyst layer have focused on developing structural models and 3-D interpretations of water management in the catalyst layer.(1-4) Most of the research shows a similar structure for carbon based catalyst layer in which, there are carbon particles deposited with nanoparticles of platinum. These carbon particles form agglomerates, which are suspended in ionomer to create pores known as secondary pores. $(2,5,6)$ Eikerling (2) described the structure of the catalyst layer in a PEM fuel cell to have ionomer strands built into the agglomerates. Eikerling (2) explains, having the ionomer strands in the agglomerate will help with the transfer of reactants to the catalyst sites. The nature and structure of the PEM fuel cell catalyst layer is still not agreed upon by the fuel cell community.

The thickness and pore size of the catalyst layer may vary depending upon the fabrication method. The thickness of the catalyst layer is generally between $10-20 \mu \mathrm{m} .(2,5,6)$ The pore size within the catalyst layer is not well established and can vary significantly. Uchida 
et al. (5) showed the secondary pore size, pores between agglomerates, to have diameters of $0.04-1 \mu \mathrm{m}$. Other researchers have shown secondary pore sizes from 10-200nm. $(2,6)$

Experimental studies of percolation in the catalyst layer are a relatively recent topic. The data available is more focused on water management to increase cell performance while decreasing degradation.(7-9) An anti-flooding catalyst layer was created and tested by means of in-situ studies to see the performance in the fuel cell.(7) Yim et al. (8) developed membrane electrode assembly's (MEA) with different cathode catalyst layers (CCL) micro-structures, which revealed that diffusion resistance is reduced from the water accumulation in the pores by capillary water equilibrium as mean pore size and volume increase.(8) The water balance between accumulation and discharging in pores is dependent upon the pore structure of the CCL, which reveals more stable cell performance for the CCLs with greater pore sizes and larger pore volumes through water management. Stevens et al. (9) studied the stability of the PEM fuel cell catalysts.(9) They explored both ex situ and in situ degradation testing with the catalyst layer on cell performance through comparison of reactivity of platinum-loaded carbons composed from either a BP2000 or XC72 carbon support. The BP2000 oxidized more rapidly than the XC72 because of the BP2000 has a much larger surface area, which leads to smaller particles of Pt per unit area of the carbon surface.(9)

The main objective of this study is to investigate liquid transport in the catalyst layer of a PEM fuel cell by means of percolation.

\section{Experimental Setup}

Two different catalyst layer samples transferred to a Nafion membrane, were used for the percolation study. Ballard Power Systems supplied the catalyst layers for this study. The samples are referred to as sample A and sample B. An SEM image of both samples can be seen in Fig 1. The composition of the samples was identical, but they were produced using different processes. Both samples contained a membrane with a backing layer which made the structure much more rigid and thicker. The thickness of the catalyst layers was $12 \mu \mathrm{m}$ on a $24 \mu \mathrm{m}$ thick membrane.

A $4 \mathrm{~cm} \times 5.5 \mathrm{~cm}$ section of the catalyst layer was placed between two platens made of polymethylmethacrylate (PMMA). The catalyst layer sample is placed between the platens, as is shown in Fig 2. This type of test setup is referred to as a pseudo-Hele-Shaw setup and is similar to that described in Medici and Allen (10). The platens containing the sample are compressed to a pressure of 10 psi via an air cylinder. A Panasonic GP-KS125 CCD camera recorded images at $0.9,1.8,4.5$, and 9 frames per second (fps). The conditions that were set for the testing of the samples can be seen in Table (1). Pressure data was synchronized with video imaging of the percolation. Images were collected using a EPIX PIXCI frame grabber and XCAP software. The liquid is being injected into the catalyst layer, through polytetrafluoroethylene (PTFE) micro-tubing. The tubing is connected to the bottom platen that has a flow passage for liquid injection. The fluid is injected into the center of the sample. A syringe pump, Harvarad Apparatus model 944, was used at three different speeds with a $2.5 \mathrm{ml}$ gas-tight Hamilton syringe. A pressure transducer, Omegadyne ${ }^{\circledR}$ model PX209-30V15G10V, read the percolation pressure within the catalyst layer at intervals of $0.04,0.02$, and 0.01 seconds depending on the fluid injection rate.

The fluid chosen for percolation tests in the catalyst layer is FC-3283, a Flourinert ${ }^{\mathrm{TM}}$ from 3M. FC-3283 is a liquid with stable transport properties over time, is colorless, clear, 


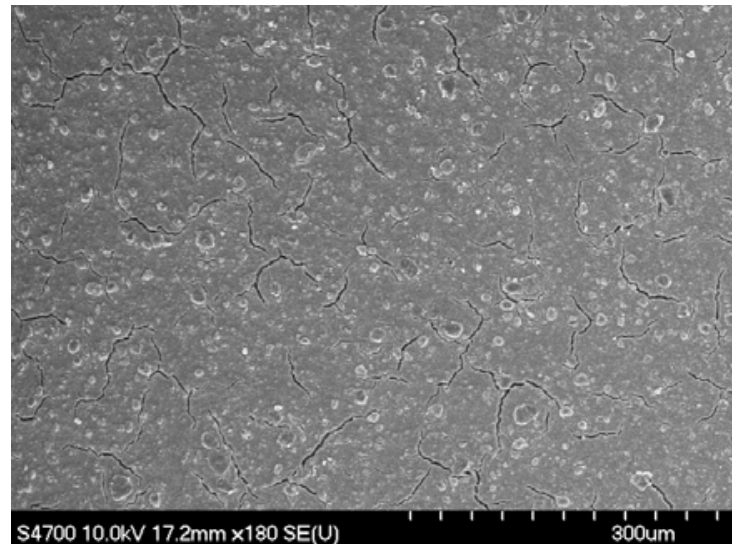

(a) Sample A at $180 \mathrm{x}$

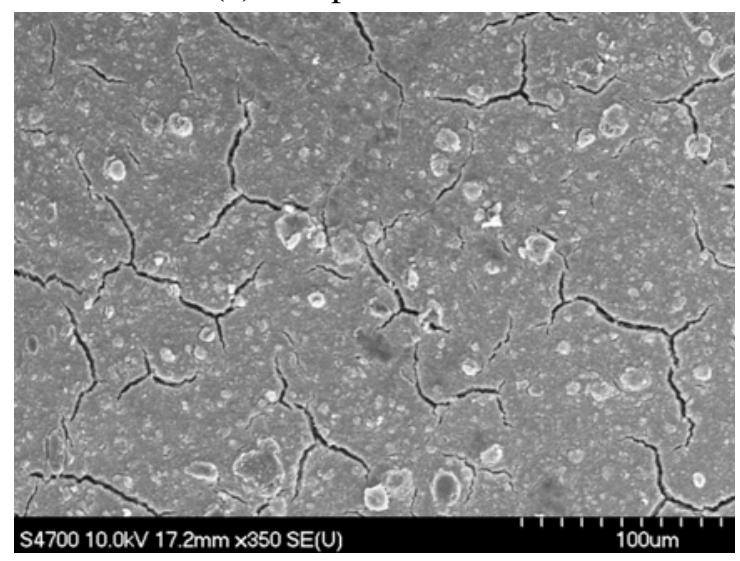

(c) Sample A at 350x

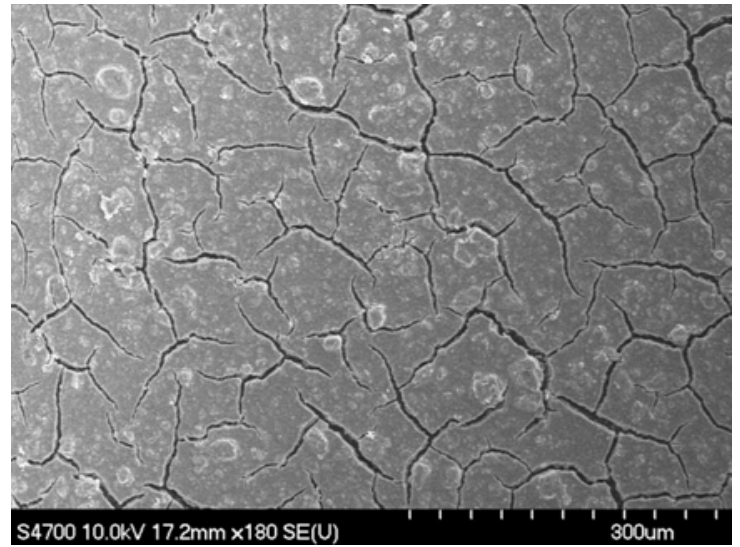

(b) Sample B at $180 \mathrm{x}$

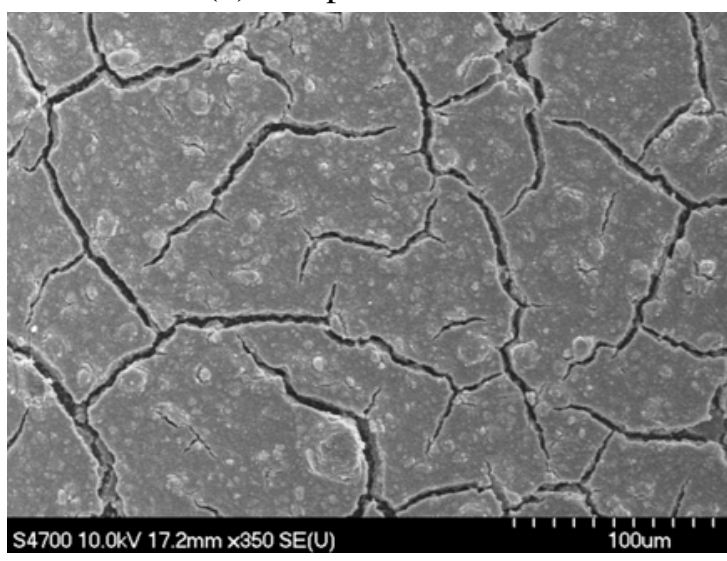

(d) Sample B at 350x

Figure 1: SEM image of the catalyst layers tested. On the left is sample A, on the right is sample B. 


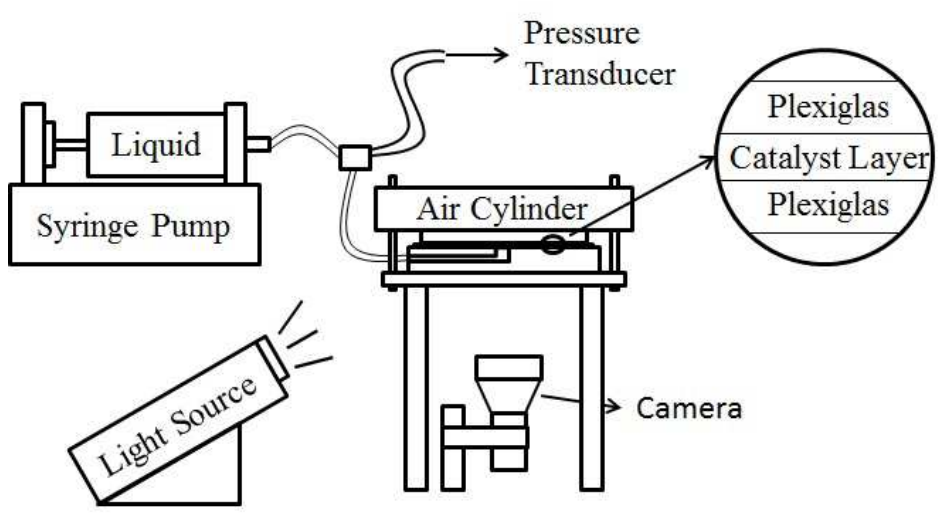

Figure 2: Schematic representation of the experimental setup that is used for testing the percolation in the catalyst layer.

thermally and chemically stable, and is a fully-flourinated fluid.(11) FC-3283 is not a solvent to the ionomer, nor is there any uptake of FC-3283 in the ionomer of in Nafion. FC3283 is a wicking fluid to the catalyst layer, resulting in spontaneous imbibiton.

Table 1: Table of the test conditions ran on the two catalyst layer.

\begin{tabular}{|c|c|c|}
\hline $\mathrm{Q}\left(\mathrm{mls}^{-1}\right)$ & Frame Rate $(\mathrm{fps})$ & Data Acquisition $(\mathrm{Hz})$ \\
\hline $9.483 \times 10^{-4}$ & 0.9 & 25 \\
$18.75 \times 10^{-4}$ & 1.8 & 50 \\
$37.08 \times 10^{-4}$ & 4.5 & 100 \\
$37.08 \times 10^{-4}$ & 9 & 100 \\
\hline
\end{tabular}

\section{Observations}

The flow regime observed during percolation is stable displacement as defined by Lenormand $(12,13)$. The stable displacement can be seen in detail in Fig 3. The pressure plots for sample A are shown in Fig 4. Three different flow rates were tested on the sample, while keeping the sample compression constant. Two separate sets of tests are shown in Fig 4 for a single sample A, showing excellent repeatability. As the fluid is entering the channel the pressure is relatively constant. Once the liquid reaches the catalyst layer interface, a pressure rise occurs. A trend in increasing pressure can be seen in the plots with increasing flow rate. An increase in flow rate by a factor of 2 results in a doubling of the pressure increase. A second increase in flow rate by a factor of 2 does not result in another doubling of pressure rise.

The testing for sample B was similar to the sample A. The percolation pressure plots for sample B can be seen in Fig 5. The plots show that sample B had a small drop in pressure at the onset of percolation in every test. The FC-3283 wicks into the catalyst layer creating a negative pressure at the beginning of percolation. The pressure starts to increase after the liquid has wicked into all available pores and is then being displaced throughout the catalyst layer by the syringe pump. The percolation pressure is not as high in sample B as sample A, and the increase in percolation pressure with increasing flow rate is not observed in sample B. The drop in pressure becomes less pronounced as the flow rate is increased. 


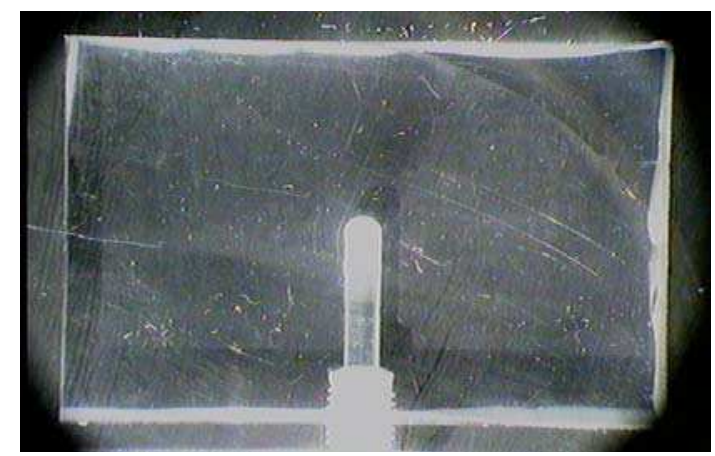

(a) Before percolation, 0 seconds

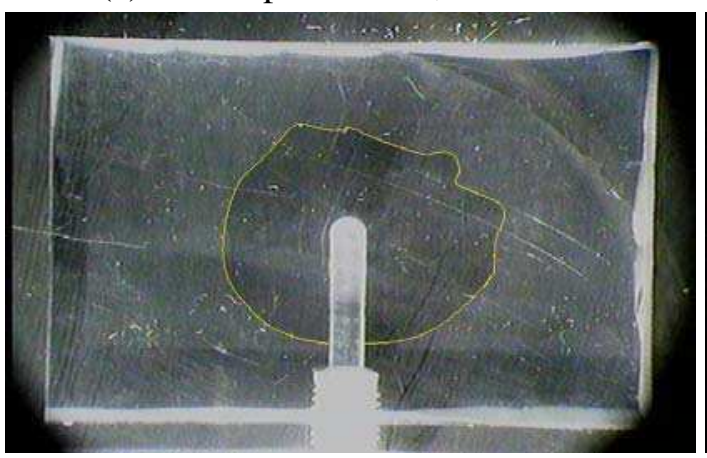

(c) 1.77 seconds

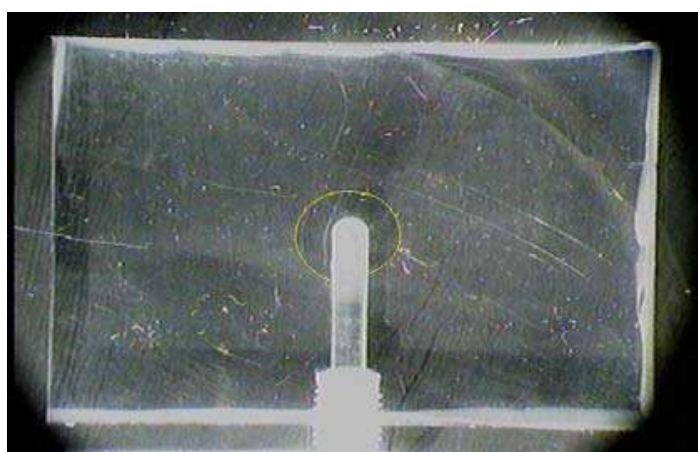

(b) 0.22 seconds

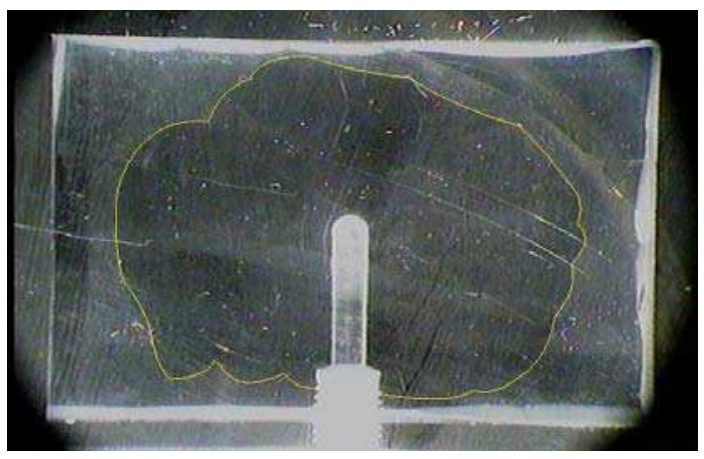

(d) End of test, 3.66 seconds

Figure 3: Percolation in sample A of catalyst layers.

\section{Conclusion}

A working apparatus has been built for investigating PEM fuel cell catalyst layer percolation, while studying the imbibition in the catalyst layer as well. The visualization on the apparatus works well for seeing the saturation occurring during testing. The images taken from testing will be later examined and the saturation will be looked at versus the pressure. From the plots that were shown in the above study, the data is shown to be repeatable over a number of tests. As the flow rate is doubled the data results in a higher pressure, however when the flow rate is doubled again the pressure cannot be seen to have increased from the plot.

\section{Acknowledgments}

This work was partially supported under U.S. Department of Energy contract DEEE0000466 in cooperation with Ballard Power Systems. Catalyst layer samples provided by Ballard Power Systems. S. Stacy would like to acknowledge the guidance and support of Ezequiel F. Medici. 


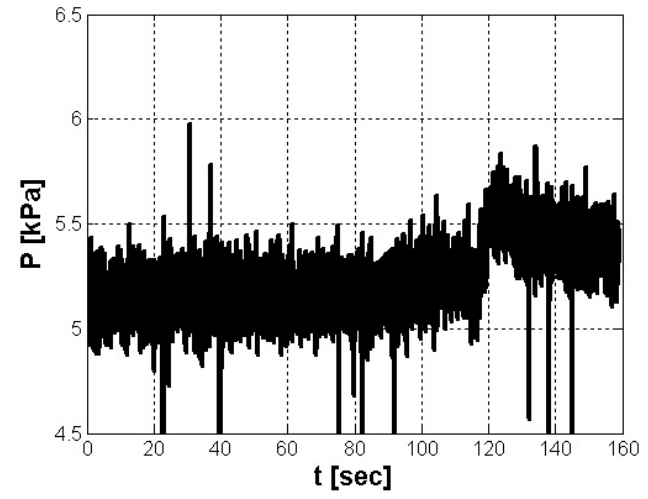

(a) $1^{\text {st }}$ test at $9.483 \times 10^{-4} \mathrm{mLs}^{-1}$

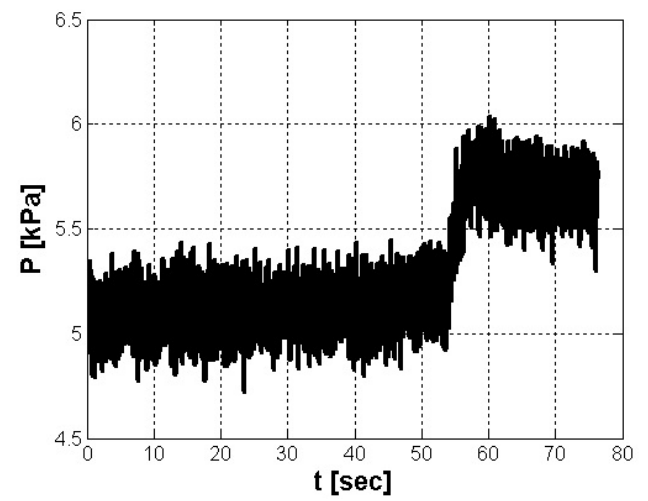

(c) $1^{\text {st }}$ test at $18.758 \times 10^{-4} \mathrm{mLs}^{-1}$

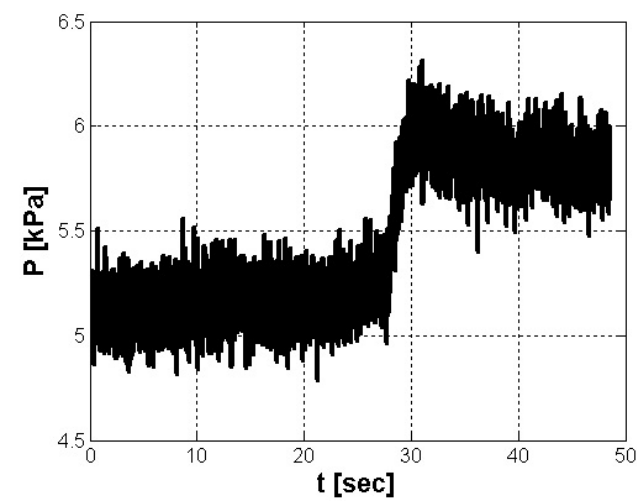

(e) $1^{\text {st }}$ test at $37.08 \times 10^{-4} \mathrm{mLs}^{-1}$

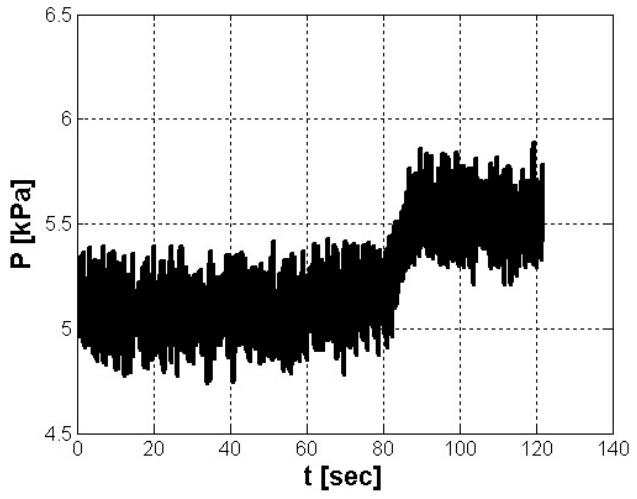

(b) $2^{\text {nd }}$ test at $9.483 \times 10^{-4} \mathrm{mLs}^{-1}$

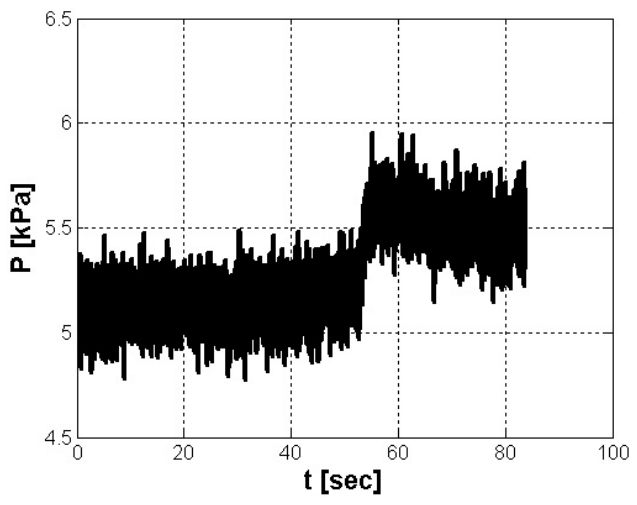

(d) $2^{\text {nd }}$ test at $18.75 \times 10^{-4} \mathrm{mLs}^{-1}$

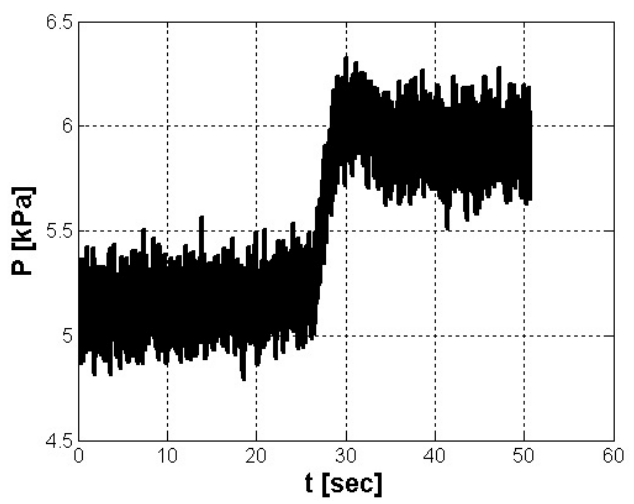

(f) $2^{\text {nd }}$ test at $37.08 \times 10^{-4} \mathrm{mLs}^{-1}$

Figure 4: Percolation pressure plot of sample A of catalyst layer. The tests were conducted at three different flow rates $9.4 \times 10^{-4}, 18.69 \times 10^{-4}, 37.09 \times 10^{-4} \mathrm{mLs}^{-1}$. 


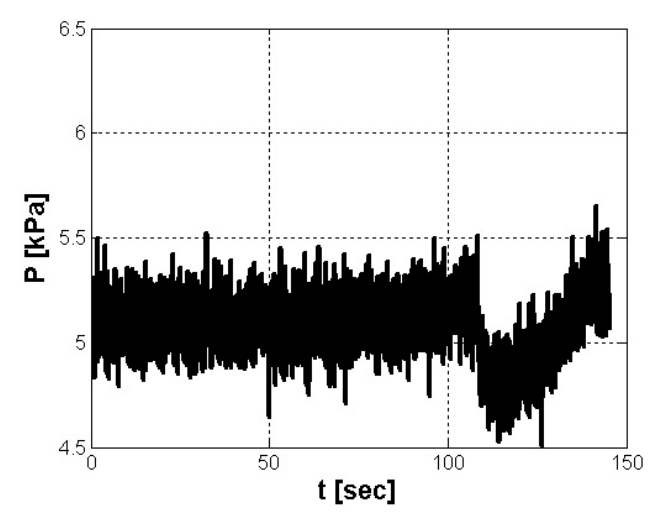

(a) $1^{\text {st }}$ test at $9.483 \times 10^{-4} \mathrm{mLs}^{-1}$

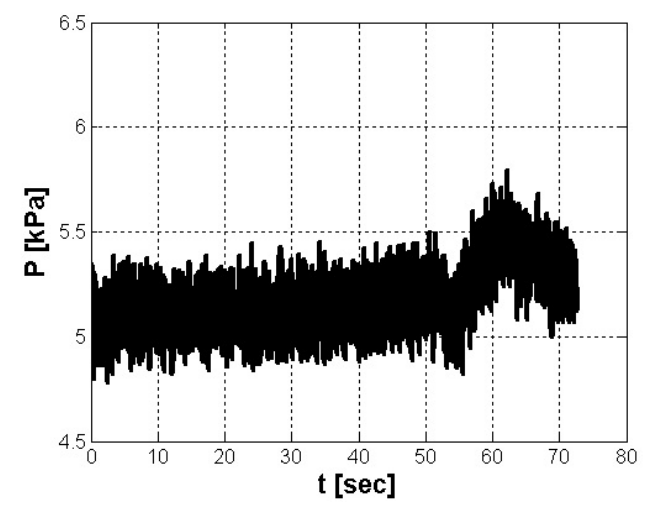

(c) $1^{\text {st }}$ test at $18.75 \times 10^{-4} \mathrm{mLs}^{-1}$

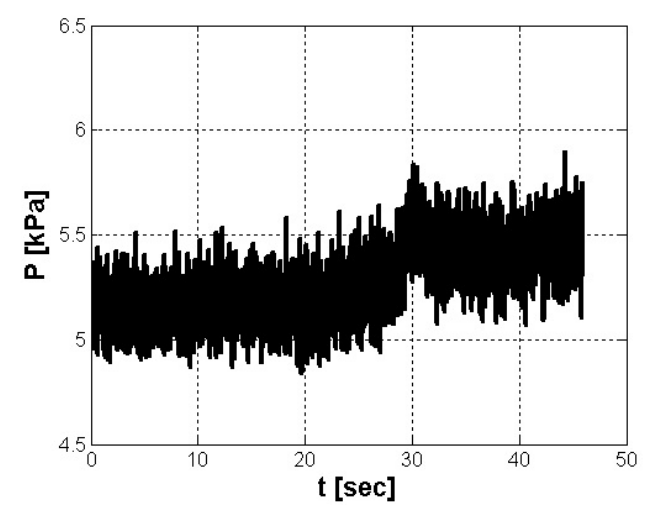

(e) $1^{\text {st }}$ test at $37.08 \times 10^{-4} \mathrm{mLs}^{-1}$

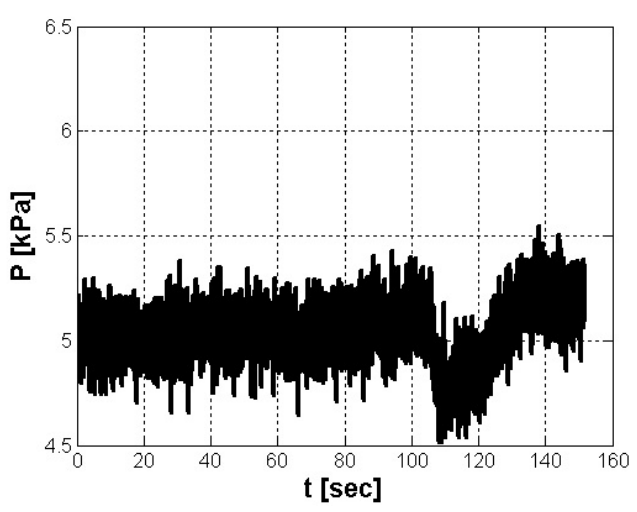

(b) $2^{\text {nd }}$ test at $9.483 \times 10^{-4} \mathrm{mLs}^{-1}$

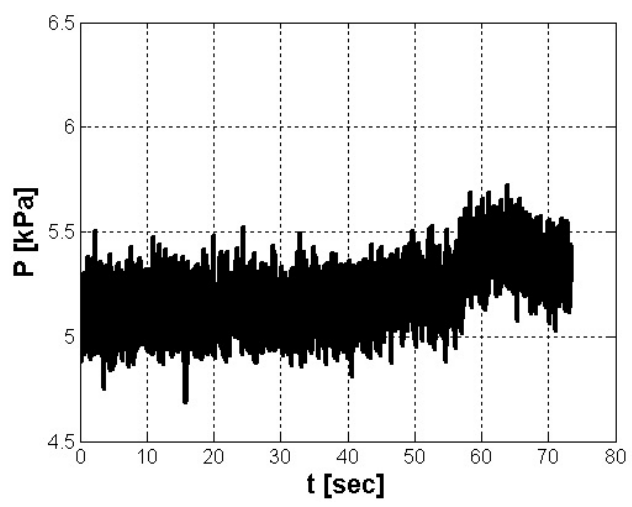

(d) $2^{\text {nd }}$ test at $18.75 \times 10^{-4} \mathrm{mLs}^{-1}$

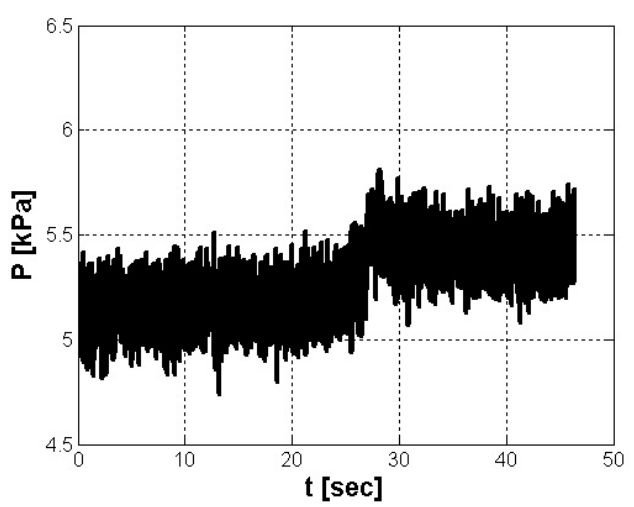

(f) $2^{\text {nd }}$ test at $37.08 \times 10^{-4} \mathrm{mLs}^{-1}$

Figure 5: Percolation pressure plot of sample B of catalyst layer. The tests were conducted at three different flow rates $9.4 \times 10^{-4}, 18.69 \times 10^{-4}, 37.09 \times 10^{-4} \mathrm{mLs}^{-1}$. 


\section{References}

1. P. K. Das, X. Li, Z. S. Liu, Int. J. Hydrogen Energy 35 (2010) 2403-2416.

2. M. Eikerling, J. Elec. Society 153 (2006) E58-E70.

3. C. Marr, X. Li, J. Power Sources 77 (1999) 17-27.

4. D. Harvey, J. G. Pharoah, K. Karan, J. Power Sources 179 (2008) 209-219.

5. M. Uchida, Y. Fukuoka, Y. Sugawara, N. Eda, A. Ohta, J. Elec. Society 143 (1996) 22452252.

6. Y. Liu, C. Ji, W. Gu, J. Jorne, H. A. Gasteiger, J. Elec. Society 158 (2011) B614-B621.

7. A. Li, S. H. Chan, N. Nguyen, Elect. Comm. 11 (2009) 897-900.

8. S. Yim, Y. Sohn, S. Park, Y. Yoon, G. Park, T. Yang, C. Kim, Electrochimica Acta 56 (2011) 9064-9073.

9. D. A. Stevens, M. T. Hicks, G. M. Haugen, J. R. Dahn, J. Elec. Society 152 (2005) A2309A2315.

10. E. F. Medici, J. S. Allen, J Power Sources 191 (2009) 417-427.

11. D. L. Fritz, An Implementation of a phenomenological evaporation model into a porous network simulaiton for water management in low temperature fuel cells, Ph.D. thesis, Michigan Technological University, 2012.

12. R. Lenormand, E. Touboul, C. Zarcone, J Fluid Mechanics 189 (1988) 165-187.

13. R. Lenormand, J Physics-Condenced Matter 2 (1990) SA79-SA88. 